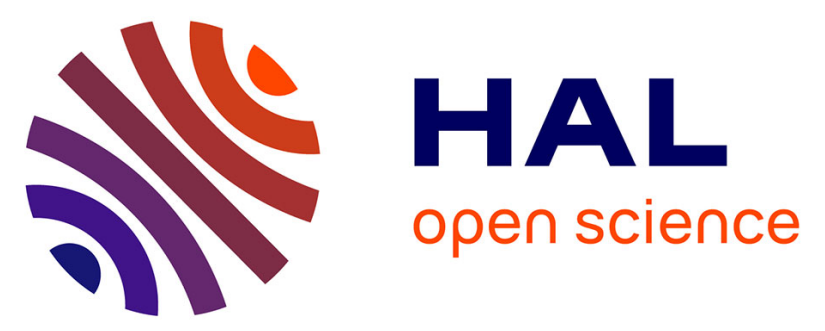

\title{
Nonlinear supersonic post-flutter motion of panels with adjacent bays and thermal effects
}

\author{
Thiago A.M. Guimarães, Leonardo Sanches, Flávio D. Marques
}

\section{To cite this version:}

Thiago A.M. Guimarães, Leonardo Sanches, Flávio D. Marques. Nonlinear supersonic post-flutter motion of panels with adjacent bays and thermal effects. International Journal of Non-Linear Mechanics, 2020, 125, pp.103545-103558. 10.1016/j.ijnonlinmec.2020.103545 . hal-03032906

\section{HAL Id: hal-03032906 https://hal.science/hal-03032906}

Submitted on 1 Dec 2020

HAL is a multi-disciplinary open access archive for the deposit and dissemination of scientific research documents, whether they are published or not. The documents may come from teaching and research institutions in France or abroad, or from public or private research centers.
L'archive ouverte pluridisciplinaire HAL, est destinée au dépôt et à la diffusion de documents scientifiques de niveau recherche, publiés ou non, émanant des établissements d'enseignement et de recherche français ou étrangers, des laboratoires publics ou privés. 


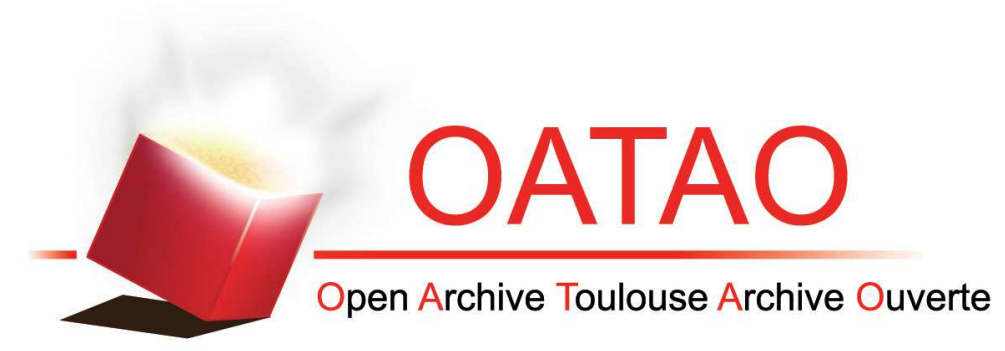

\section{Open Archive Toulouse Archive Ouverte (OATAO)}

OATAO is an open access repository that collects the work of some Toulouse researchers and makes it freely available over the web where possible.

This is an author's version published in: https://oatao.univ-toulouse.fr/26918

Official URL: https://doi.org/10.1016/j.ijnonlinmec.2020.103545

\section{To cite this version :}

Guimarães, Thiago A.M. and Sanches, Leonardo and Marques, Flávio D. Nonlinear supersonic post-flutter motion of panels with adjacent bays and thermal effects. (2020) International Journal of Non-Linear Mechanics, 125. 103545-103558. ISSN 0020-7462

Any correspondence concerning this service should be sent to the repository administrator: tech-oatao@listes-diff.inp-toulouse.fr 


\title{
Nonlinear supersonic post-flutter motion of panels with adjacent bays and thermal effects
}

\author{
Thiago A.M. Guimarães ${ }^{\mathrm{a}}$, Leonardo Sanches ${ }^{\mathrm{b}}$, Flávio D. Marques ${ }^{\mathrm{c}, *}$ \\ ${ }^{a}$ School of Mechanical Engineering, Federal University of Uberlândia - UFU, Brazil \\ ${ }^{\mathrm{b}}$ Université de Toulouse, ICA, CNRS, ISAE-Supaero, Toulouse, France \\ ${ }^{\text {c }}$ São Carlos School of Engineering, University of São Paulo, São Carlos, SP, Brazil
}

\begin{tabular}{|c|c|}
\hline & A B S T R A C T \\
\hline $\begin{array}{l}\text { Keywords: } \\
\text { Aeroelasticity } \\
\text { Supersonic panel flutter } \\
\text { Multi-bay panel flutter } \\
\text { Thermo-buckling loading } \\
\text { Nonlinear dynamics } \\
\text { Rayleigh-Ritz method }\end{array}$ & $\begin{array}{l}\text { Aerospace vehicle structures in the supersonic regime flight have their outer skin subjected to unsteady } \\
\text { aerodynamic and thermal loading, which may lead to aeroelastic instability. Typical aerospace structures } \\
\text { are built as multiple adjacent panels, the so-called multi-bay configuration, but early efforts to predict the } \\
\text { supersonic flutter were based on a single panel arrangement. This work evaluates the aeroelastic behavior } \\
\text { of supersonic multi-bay fluttering panels under thermal effects, aiming to improve the understanding of } \\
\text { adjacent panels interaction in the nonlinear regime. The aeroelastic model is established by using the first-order } \\
\text { quasi-steady piston theory in conjunction with isotropic panel model using the von Kármán's assumptions to } \\
\text { account for geometrical nonlinearities. The Newmark time-integration method is used to evaluate the resulting } \\
\text { equations of motion. The Hopf bifurcation behavior that determines the flutter onset, thermo-buckling loading, } \\
\text { phase portrait plots, and bifurcation diagrams for two adjacent panels are presented. The numerical results } \\
\text { show the detrimental aspect of thermal loading in the aeroelastic behavior of fluttering panels, and the new } \\
\text { findings corroborate with some recent studies that highlight the difference in the nonlinear flutter behavior } \\
\text { between a single panel and multi-bay panels. Moreover, the existence of limit cycle oscillations amplitude } \\
\text { jumps from a certain level of flow dynamic pressure is also observed. The multi-bay panels configuration also } \\
\text { shows the anticipation of the buckled to the limit cycle oscillation solutions, when compared with a single } \\
\text { panel analysis. Results indicate that simplified single bay panel assumptions can underestimate the post-flutter } \\
\text { oscillations amplitudes of the adjacent bay. Such dynamic behavior may lead to a negative impact on aircraft } \\
\text { structural design and fatigue life estimation. }\end{array}$ \\
\hline
\end{tabular}

\section{Introduction}

The dynamic instability of plates and shells under the effects of supersonic flow has been investigated since the 1950s. The so-called panel flutter is an aeroelastic problem occurring in parts of the aircraft external skin, leading to fatigue damages and possible collapse of the structure [1-3]. Most of the earlier panel flutter analyses were performed through numerical simulations with few validations, as experimental data were not easily available. Moreover, the flutter problem was mostly predicted admitting a single panel [4,5]. Real aircraft structures are assembled in such way that in practice one has adjacent panels arrangement, that is, multi-bay panels.

Recently, the multi-bay panel flutter has been revisited by Pacheco and co-workers [6-8], being the first to present a nonlinear analysis based on the finite element method. The multi-bay panel flutter was initially investigated in the 1960s by Dowell [9,10], Rodden [11], and Lock and Farkas [12] using linear structure modeling. The conclusions from these pioneering research show that the flutter boundary was determined by the single panel solution alone. The boundary is only significantly affected when a large number of bays is taken into account.

The first nonlinear analysis of the multi-bay panel flutter was presented by Pacheco et al. [6]. They investigated several arrangements of two- and three-bay with simply supported boundary conditions between the adjacent panels. The nonlinear equation of motion was modeled with a high-order finite element formulation and von Kármán strain-displacement relations for thin isotropic plates jointly with unsteady aerodynamics given by the first-order piston model. The critical flutter dynamic pressure coincides with the linear prediction, but the post-flutter mechanism is affected by adjacent panels coupling. As a consequence, the evolution in dynamic pressure leads to amplitude jumps in the limit cycle oscillations. Moreover, coexisting limit cycles sensitive to the initial conditions were also observed in the region of the amplitude jumps.

\footnotetext{
* Corresponding author.

E-mail addresses: thiagoamg@ufu.br (T.A.M. Guimarães), leonardo.sanches@isae-supaero.fr (L. Sanches), fmarques@sc.usp.br (F.D. Marques).
} 
Pacheco et al. [7] solved the nonlinear supersonic panel flutter of multi-bay arrangements using a nonlinear beam between the adjacent bays, which works as an elastic stringer. The finite element method was employed considering the Mindlin plate model for the panel and the Timoshenko beam theory for the stiffeners. Geometrical nonlinearity was included in both plate and beam through the von Kármán strain-displacement relations. The unsteady aerodynamic loading was calculated with the first-order piston theory. The equations of motion were solved in the time domain with the Newmark integration approach. The results demonstrate that the multi-bay problem follows similar flutter mechanisms for simply supported and stiffened adjacent panels. Moreover, jumps on the limit cycle amplitude are also detected in the post-flutter regime. The stiffener cross-sectional geometry plays an important role in the post-flutter mechanism and can be designed to diminish oscillations amplitudes. Pacheco et al. [8] also performed an energy approach to the analysis of the multi-bay panel flutter. They investigated how mechanical energy is distributed among the multi-bays and the elastic stiffener.

Most of the works mentioned before were based on structural dynamics modeling using the finite element method. Despite all the advantages of the finite element approaches, a significant disadvantage relies on high computational cost when time integration of the resulting nonlinear equations of motion is necessary. An alternative form of overcoming the computational cost can be achieved with the application of the Rayleigh-Ritz method. The Rayleigh-Ritz method is a semi-analytical approach that consists of assuming admissible functions for the three displacements fields of a plate, forming the approximate solutions for the respective set of nonlinear partial derivative equations. The method allows the evaluation in wide range geometry of linear and nonlinear structures with computational efficiency, as the overall order of the nonlinear aeroelastic system is usually lower than the finite element model counterparts.

To the best of the author's knowledge, a nonlinear aeroelastic analysis of multi-bay panel flutter with thermal buckling has not been available in the literature. Indeed, as shown for a single panel, the operational temperature variation leads to mechanical constraints on the structure that may affect its dynamics significantly [4]. Moreover, the application of the Rayleigh-Ritz approach to the multi-bay problem is also a novelty that brings the advantage of faster numerical integration of the aeroelastic equations regarding supersonic flutter analyses. Recently, Guimarães et al. [13] verified the applicability and brought forward the computational performance advantages of the semi-analytical Ritz-type model in the analysis of multi-bay composite laminates supersonic panel flutter. Guimarães et al. [13] compared the Rayleigh-Ritz (RR) with the finite element method (FEM) revealing that the RR approach solved the two-bay supersonic flutter problem with no thermal effects in approximately a fifth of the time used for FEM. The analysis also included the post-flutter jump prediction capabilities of the RR approach regarding the number of modes and adopted boundary conditions.

To fill the gaps of the nonlinear supersonic panel flutter analysis of multiple adjacent bay assemble including thermal loading, the Rayleigh-Ritz method is used to analyze an isotropic thin panel subjected to supersonic flow. The thermal effects are incorporated into the model through the in-plane normal and shear loading. The connection between two adjacent bays is achieved employing a penalty approach, in which the assembly relations compatibility is guaranteed, which results in the continuous membrane and bending loads from one panel to another. The unsteady aerodynamic loading is modeled with the first-order piston theory and incorporated to the aeroelastic equations. The Newmark method is used to assess the time integration of the aeroelastic equations of motion. The next sections present the RayleighRitz-type model for the multi-bay panel flutter analysis, followed by a model verification using previous results encountered in the literature. The multi-bay panel flutter problem is addressed for the case of two-bay panels and thermal loading. The effects of temperature changes on the limit cycle amplitude jumps are discussed.

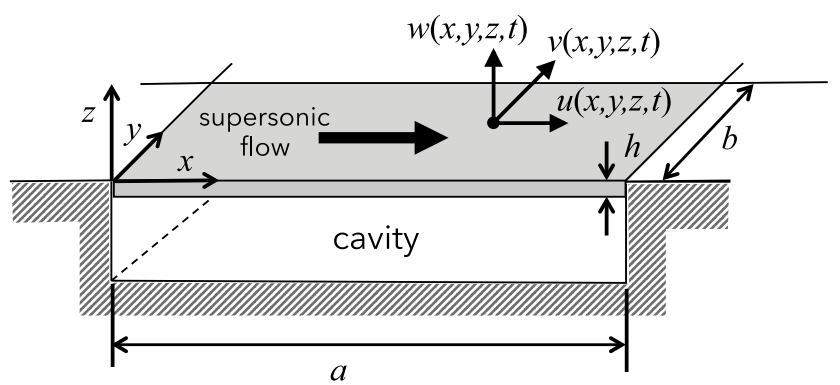

Fig. 1. Illustration of a rectangular plate model used in the supersonic flutter analysis.

\section{Nonlinear aeroelastic model}

Consider a rectangular plate of dimensions $a \times b$ separating a cavity with stagnated air and a supersonic flow field as depicted in Fig. 1. The edges of the plate are simply supported, allowing only rotations and no translation motion. The plate is modeled by assuming the plane stress state with displacements $(u, v, w)$, respectively in the $(x, y, z)$-directions. Under the Kirchhoff hypothesis, which assumes that transverse and shear strains are zero and the transverse displacement $(w)$ being independent of the transverse coordinate, $z$, the displacements $(u, v, w)$ are defined as:

$u(x, y, z, t)=u_{0}(x, y, t)-z \frac{\partial w_{0}(x, y, t)}{\partial x}$
$v(x, y, z, t)=v_{0}(x, y, t)-z \frac{\partial w_{0}(x, y, t)}{\partial y}$
$w(x, y, z, t)=w_{0}(x, y, t)$

where $u_{0}(x, y, t), v_{0}(x, y, t)$ and $w_{0}(x, y, t)$ are the mid-plane displacements.

The strain-displacement relations based on the von Kármán's nonlinear relation small strains and moderately large rotations [14] is used, resulting in the following vector:

$\boldsymbol{\epsilon}=\left\{\begin{array}{c}\epsilon_{x} \\ \epsilon_{y} \\ \gamma_{x y}\end{array}\right\}=\left\{\begin{array}{c}\frac{\partial u_{0}(x, y, t)}{\partial x}-z \frac{\partial^{2} w_{0}(x, y, t)}{\partial x^{2}}+\frac{1}{2}\left(\frac{\partial w_{0}(x, y, t)}{\partial x}\right)^{2} \\ \frac{\partial v_{0}(x, y, t)}{\partial y}-z \frac{\partial^{2} w_{0}(x, y, t)}{\partial y^{2}}+\frac{1}{2}\left(\frac{\partial w_{0}(x, y, t)}{\partial y}\right)^{2} \\ \left(\frac{\partial u_{0}(x, y, t)}{\partial x}+\frac{\partial v_{0}(x, y, t)}{\partial y}\right)-2 z \frac{\partial^{2} w_{0}(x, y, t)}{\partial x \partial y}+\frac{\partial w_{0}(x, y, t)}{\partial x} \frac{\partial w_{0}(x, y, t)}{\partial y}\end{array}\right\}$,

where $u_{0}(x, y, t)$ and $v_{0}(x, y, t)$ are the membrane displacement in the mid-plane, and $w_{0}(x, y, t)$ are out of plane mid-plane displacement, which can be conveniently split into linear terms as:

$\boldsymbol{\epsilon}^{L}=\left\{\begin{array}{c}\epsilon_{x}^{L} \\ \epsilon_{y}^{L} \\ \gamma_{x y}^{L}\end{array}\right\}=\left\{\begin{array}{c}\frac{\partial u_{0}(x, y, t)}{\partial x} \\ \frac{\partial v_{0}(x, y, t)}{\partial y} \\ \left(\frac{\partial u_{0}(x, y, t)}{\partial x}+\frac{\partial v_{0}(x, y, t)}{\partial y}\right)\end{array}\right\}$,

and

$\boldsymbol{\kappa}=\left\{\begin{array}{c}\kappa_{x} \\ \kappa_{y} \\ \kappa_{x y}\end{array}\right\}=\left\{\begin{array}{c}\frac{\partial^{2} w_{0}(x, y, t)}{\partial x^{2}} \\ \frac{\partial^{2} w_{0}(x, y, t)}{\partial y^{2}} \\ 2 \frac{\partial^{2} w_{0}(x, y, t)}{\partial x \partial y}\end{array}\right\}$,

and nonlinear one as:

$\boldsymbol{\epsilon}^{N L}=\left\{\begin{array}{c}\epsilon_{x}^{N L} \\ \epsilon_{y}^{N L} \\ \gamma_{x y}^{N L}\end{array}\right\}=\left\{\begin{array}{c}\frac{1}{2}\left(\frac{\partial w_{0}(x, y, t)}{\partial x}\right)^{2} \\ \frac{1}{2}\left(\frac{\partial w_{0}(x, y, t)}{\partial y}\right)^{2} \\ \frac{\partial w_{0}(x, y, t)}{\partial x} \frac{\partial w_{0}(x, y, t)}{\partial y}\end{array}\right\}$. 
Under the assumptions of the Classical Plate Theory [14], and considering a plate of isotropic material, the following relation between the internal forces and moments with the in-plane strains and curvatures are obtained:

$\left\{\begin{array}{c}\boldsymbol{Q} \\ \boldsymbol{M}\end{array}\right\}=\left[\begin{array}{cc}\boldsymbol{A} & \mathbf{0} \\ \mathbf{0} & \boldsymbol{D}\end{array}\right]\left\{\begin{array}{c}\boldsymbol{\epsilon}^{L}+\boldsymbol{\epsilon}^{N L} \\ \kappa\end{array}\right\}$,

in which, $\boldsymbol{M}$ is the vector of moments and $\boldsymbol{Q}$ is the vector of forces. Moreover, the membrane and bending terms are given by the matrices $\boldsymbol{A}$ and $\boldsymbol{D}$ and they are expressed, for isotropic materials, as:

$\boldsymbol{A}=\frac{E h}{1-v^{2}}\left[\begin{array}{ccc}1 & v & 0 \\ v & 1 & 0 \\ 0 & 0 & \frac{1}{2}(1-v)\end{array}\right]$,

and

$\boldsymbol{D}=\frac{h^{2}}{12} \boldsymbol{A}$

where $E$ is the modulus of Young of the plate, $v$ is the Poison's coefficient and $h$ the plate thickness.

The strain energy of the isotropic plate may be expressed by:

$$
\begin{aligned}
U= & \frac{1}{2} \int_{0}^{a} \int_{0}^{b}\left\{\boldsymbol{\epsilon}^{L}\right\}^{T} \boldsymbol{A} \boldsymbol{\epsilon}^{L} d x d y+\frac{1}{2} \int_{0}^{a} \int_{0}^{b}\left\{\boldsymbol{\kappa}^{L}\right\}^{T} \boldsymbol{D} \boldsymbol{\kappa}^{L} d x d y+ \\
& +\frac{1}{2} \int_{0}^{a} \int_{0}^{b}\left\{\boldsymbol{\epsilon}^{L}\right\}^{T} \boldsymbol{A} \boldsymbol{\epsilon}^{N L} d x d y+\frac{1}{2} \int_{0}^{a} \int_{0}^{b}\left\{\boldsymbol{\epsilon}^{N L}\right\}^{T} \boldsymbol{A} \boldsymbol{\epsilon}^{L} d x d y+ \\
& +\frac{1}{2} \int_{0}^{a} \int_{0}^{b}\left\{\boldsymbol{\epsilon}^{N L}\right\}^{T} \boldsymbol{A} \boldsymbol{\epsilon}^{N L} d x d y .
\end{aligned}
$$

Regarding the kinetic energy, it is used the hypotheses of the Kirchhoff theory [15], which is adequate for thin plates:

$T=\frac{1}{2} \int_{0}^{h} \int_{0}^{b} \int_{0}^{a} \rho_{0}\left[\dot{u}^{2}+\dot{v}^{2}+\dot{w}^{2}\right] d x d y d z$,

where $\rho_{0}$ is the plate material density.

The thermal effects are incorporated in the model throughout inplane normal and shear loads $\left(N_{x x}, N_{y y}, N_{x y}\right)$ defined as:

$\boldsymbol{N}_{\Delta T}=\left[\begin{array}{lll}N_{x x} & N_{y y} & N_{x y}\end{array}\right]^{T}=\boldsymbol{A} \Delta T\left[\begin{array}{lll}\alpha_{x} & \alpha_{y} & \alpha_{x y}\end{array}\right]^{T}$,

where $\left[\begin{array}{lll}\alpha_{x} & \alpha_{y} & \alpha_{x y}\end{array}\right]^{T}$ are the thermal expansion coefficients and $\Delta T$ is represents the temperature variation. is:

The corresponding potential energy due to thermal-induced loads

$$
U_{\Delta T}=-\frac{1}{2} \int_{0}^{a} \int_{0}^{b}\left[N_{x x}\left(\frac{\partial w}{\partial x}\right)^{2}+N_{y y}\left(\frac{\partial w}{\partial y}\right)^{2}+2 N_{x y} \frac{\partial w}{\partial x} \frac{\partial w}{\partial y}\right] d x d y
$$

The unsteady aerodynamic pressure distribution over the panel is modeled with the first-order piston theory [16], which performs satisfactorily within the range of Mach admitted in this investigation [17, 18], namely,

$\Delta P(x, y, t)=\frac{2 q_{d y n}}{\sqrt{M^{2}-1}}\left[\left(\frac{\partial w}{\partial x}+\frac{M^{2}-2}{M^{2}-1} \frac{1}{U_{\infty}} \frac{\partial w}{\partial t}\right)\right]$,

where $q_{d y n}, M$ and $U_{\infty}$ are the dynamic pressure, Mach number, and flow velocity, respectively.

Then, the variation of the virtual work done by the aerodynamic loading is attained by a complicated nonlinear dependence on the surface motion as demonstrated in Amabili and Breslavsky [19] and Amabili [20]. Here, an approximation with respect to the normal surface displacement is assumed and represented as,

$\delta W=\int_{0}^{a} \int_{0}^{b} \Delta P(x, y, t) \delta w d x d y$.

For the approximate solution of a simply supported immovable edges panel, the displacement field are evaluated using a set of Ritz functions as generalized coordinates [21], that is,

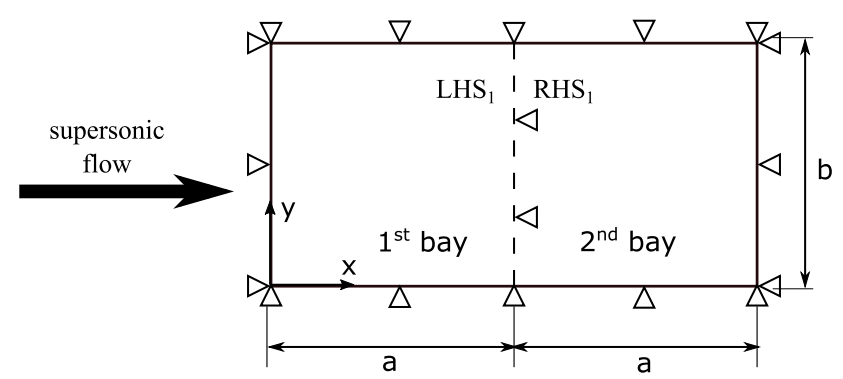

Fig. 2. Simply supported multi-bay configuration assembly.

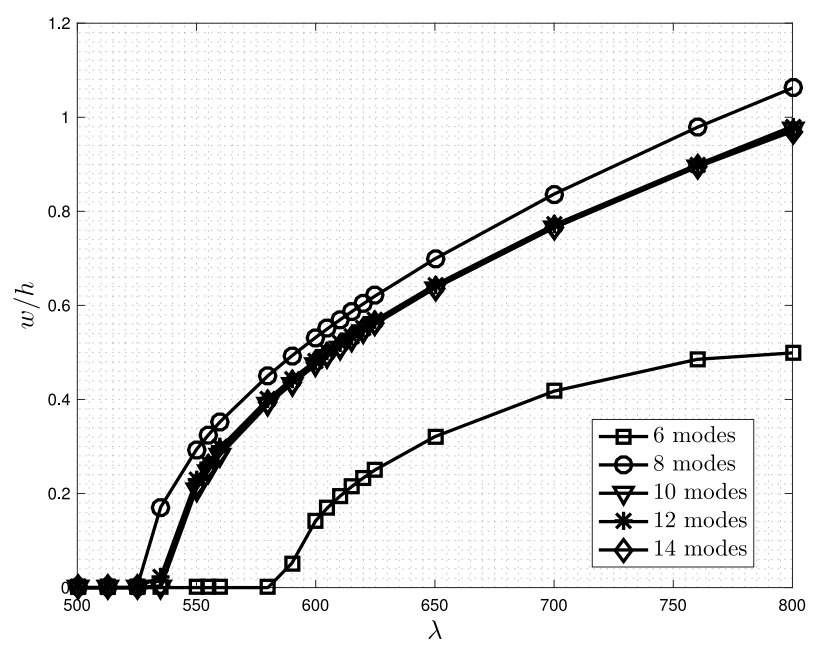

Fig. 3. Flutter onset point and amplitude convergence study with respect to the dynamic pressure.

$u_{0}(x, y, t)=\sum_{m=0}^{M_{u}} \sum_{n=0}^{N_{u}} q u_{m n}(t) \sin \left(m \frac{x \pi}{a}\right) \sin \left(n \frac{y \pi}{b}\right)=\sum_{m=0}^{M_{u}} \sum_{n=0}^{N_{u}} S_{m n}^{u}(x, y) q u_{m n}(t)$

$v_{0}(x, y, t)=\sum_{m=0}^{M_{v}} \sum_{n=0}^{N_{v}} q v_{m n}(t) \sin \left(m \frac{x \pi}{a}\right) \sin \left(n \frac{y \pi}{b}\right)=\sum_{m=0}^{M_{v}} \sum_{n=0}^{N_{v}} S_{m n}^{v}(x, y) q v_{m n}(t)$,

$w_{0}(x, y, t)=\sum_{m=0}^{M_{w}} \sum_{n=0}^{N_{w}} q w_{m n}(t) \sin \left(m \frac{x \pi}{a}\right) \sin \left(n \frac{y \pi}{b}\right)=\sum_{m=0}^{M_{w}} \sum_{n=0}^{N_{w}} S_{m n}^{w}(x, y) q w_{m n}(t)$,

where $q(i)_{m n}$ and $S_{m n}^{(i)},(i)=[u, v, w]$ represent the generalized coordinate and the assumed mode shape function used for the Rayleigh-Ritz expansion of the displacement fields along the directions $x, y$, and $z$, respectively.

Eqs. (15) to (17) can be summarized in matrix notation as:

$\left\{\begin{array}{c}u_{0}(x, y, t) \\ v_{0}(x, y, t) \\ w_{0}(x, y, t)\end{array}\right\}=\left[\begin{array}{ccc}\boldsymbol{S}_{u}^{T} & 0 & 0 \\ 0 & \boldsymbol{S}_{v}^{T} & 0 \\ 0 & 0 & \boldsymbol{S}_{w}^{T}\end{array}\right]\left\{\begin{array}{c}\boldsymbol{q u} \\ \boldsymbol{q v} \\ \boldsymbol{q} \boldsymbol{w}\end{array}\right\}=\boldsymbol{S}_{u, v, w} \boldsymbol{q}_{s p}$,

where $q u, q v$ and $q \boldsymbol{w}$ are vectors containing the $M_{(i)} \times N_{(i)}$, for $i=$ $[u, v, w]$ generalized coordinates, respectively. Similarly, and $\boldsymbol{S}_{u}, \boldsymbol{S}_{v}$, and $\boldsymbol{S}_{w}$ are vectors containing the assumed shape functions along $x$, $y$ and $z$ directions, respectively. The vector $\boldsymbol{q}_{s p}$ contains the generalized coordinates for modeling the nonlinear aeroelastic problem with thermal constraints for a single panel problem.

Nonetheless, the present paper aims extending the analysis for multi-bay panel configurations. Fig. 2 illustrates the multi-bay problem, where the simply supported immovable edges boundary condition is assumed for all edges and in between the bays. 


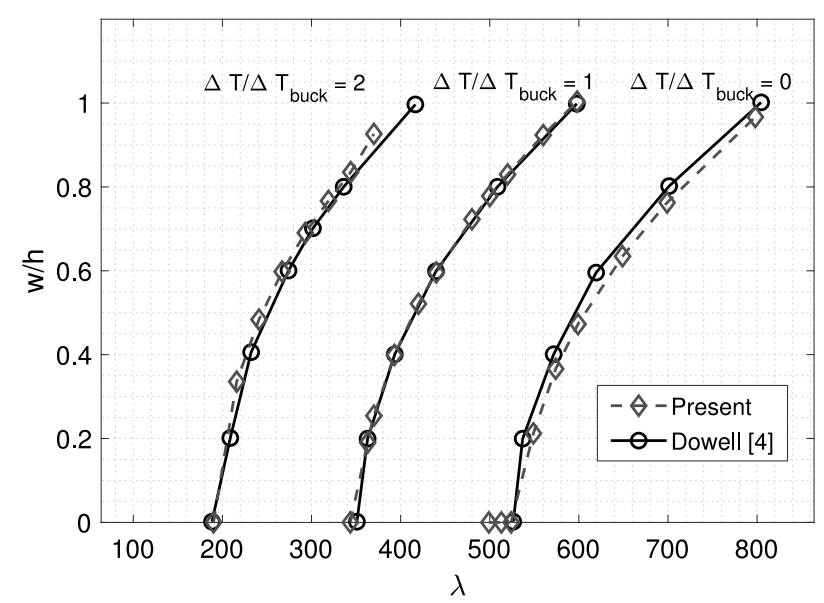

Fig. 4. Verification of limit cycle amplitudes for a simple supported panel $(a / b=1)$ considering $\mu / M=0.1$.

To model a panel formed by two adjacent plates with the RayleighRitz method, each $i$ th plate is modeled individually with respect to a global referential system and a penalty approach as described by Castro and Donadon [22] is considered. The model assembly must guarantee the following compatibility relations represented as:

$(u, v, w)_{L H S}=(u, v, w)_{R H S}$,

$\left(\frac{d w}{d x}\right)_{L H S}=\left(\frac{d w}{d x}\right)_{R H S}$,

where the subscripts $L H S$ and $R H S$ denote left-hand side and righthand side, respectively, and the penalty energy terms for each $i$ th connection line for each bay, defined as:

$U p_{i}=\int_{0}^{b}\left(\frac{d w(i a, y)_{L H S_{i}}}{d x}-\frac{d w(i a, y)_{R H S_{i}}}{d x}\right)^{2} k r_{i} d y$,

whereas $k r_{i}$ is the stiffness penalty calculated considering continuous membrane and bending loads from one bay to another, that is,

$k r_{i}=\frac{4 D_{11}^{L H S_{i}} D_{11}^{R H S_{i}}}{\left(D_{11}^{L H S_{i}}+D_{11}^{R H S_{i}}\right)\left(h^{L H S_{i}}+h^{R H S_{i}}\right)}$,

where $D_{11}$ are the first term of matrix $\boldsymbol{D}$ ( $c f$. Eq. (8)).

The aeroelastic equations of motion are then derived from the Lagrange's formulation, that is,

$\frac{d}{d t}\left(\frac{\partial T}{\partial \dot{q}}\right)-\frac{\partial T}{\partial \boldsymbol{q}}+\frac{\partial U}{\partial \boldsymbol{q}}=\frac{\partial(\delta W)}{\partial(\delta \boldsymbol{q})}$,

where $\boldsymbol{q}=\left[\boldsymbol{q}_{s p, 1}, \boldsymbol{q}_{s p, 2}\right]^{T}$ is the vector containing the generalized coordinates of the first and second single plates, respectively.

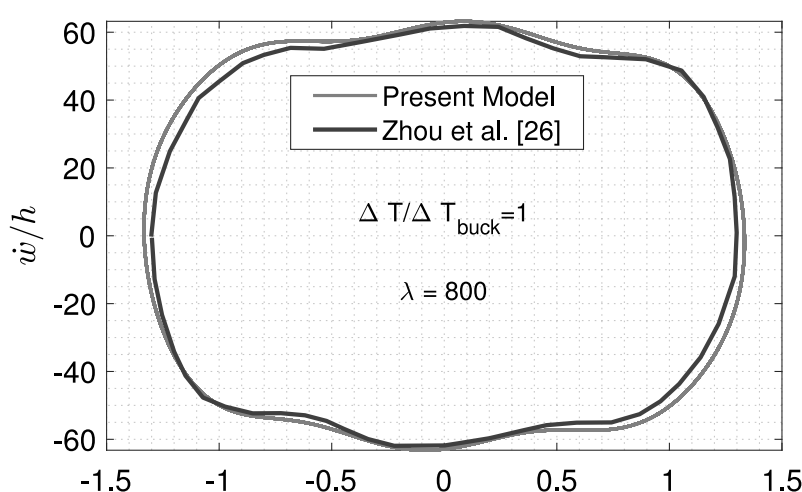

Fig. 6. Limit cycle amplitudes for a simple supported panel $(a / b=1)$ considering $\mu / M=0.1, \lambda=800$, and $\Delta T / \Delta T_{b u c k}=1.0$ and compared with results from Zhou et al. [23].

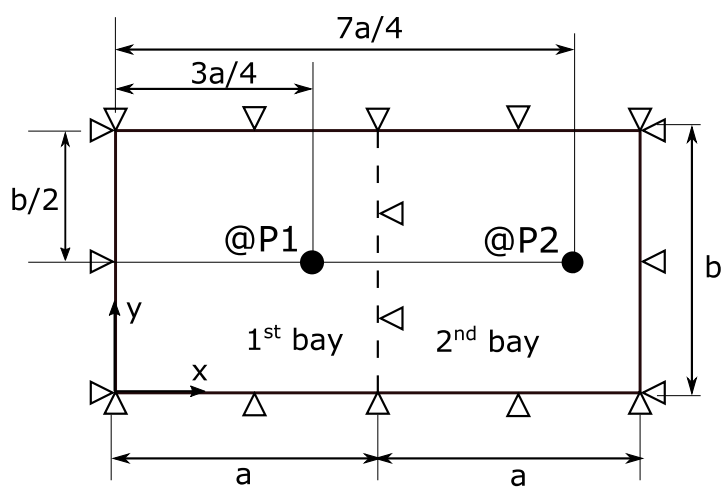

Fig. 7. Selected points for the multi-bay panel aeroelastic evaluation.

The aeroelastic equations of motion is obtained by combining the expressions of the potential energy, kinetic energy, and the work exerted by the aerodynamic loading to the Lagrange's equations. After a convenient treatment to the aeroelastic equations of motion, the following set of coupled, second-order normalized differential equations is obtained (details on each matrix is presented in Appendix), that is,

$\boldsymbol{M} \ddot{\boldsymbol{q}}(t)+g \boldsymbol{C} \dot{\boldsymbol{q}}(t)+\left[\lambda \boldsymbol{K}_{a}+\Delta T \boldsymbol{K}_{G}+\boldsymbol{K}+\boldsymbol{K}_{p_{i}}+\boldsymbol{K}_{N L_{1}}(u, v, w)+\boldsymbol{K}_{N L_{2}}(w)\right] \boldsymbol{q}(t)=\mathbf{0}$,

where $\boldsymbol{q}(t)$ is the generalized coordinate vector, $\boldsymbol{M}$ is the mass matrix, $\boldsymbol{K}_{a}$ is the aerodynamic stiffness matrix, $\lambda$ is the dimensionless dynamic
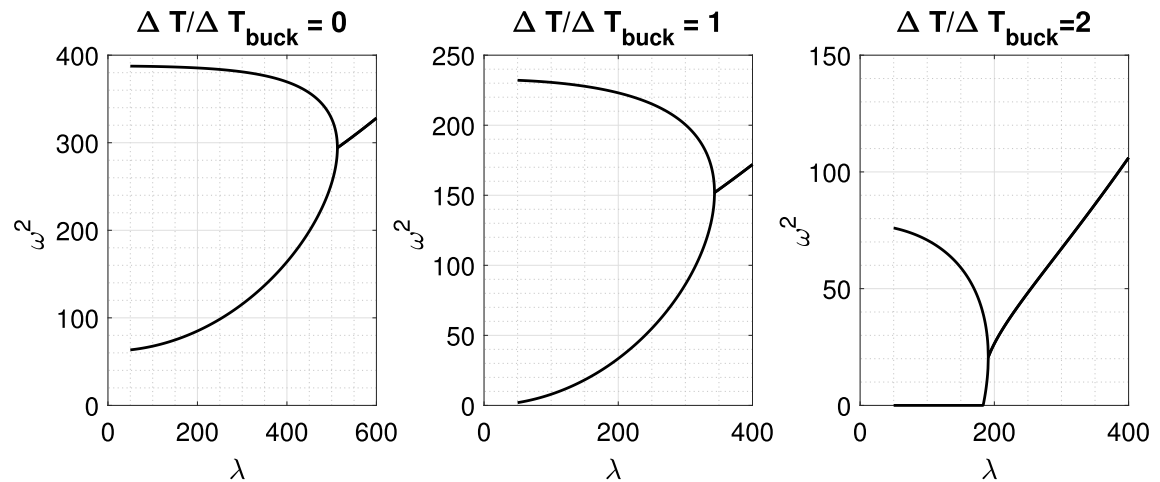

Fig. 5. Linear flutter prediction for different thermal loading. 


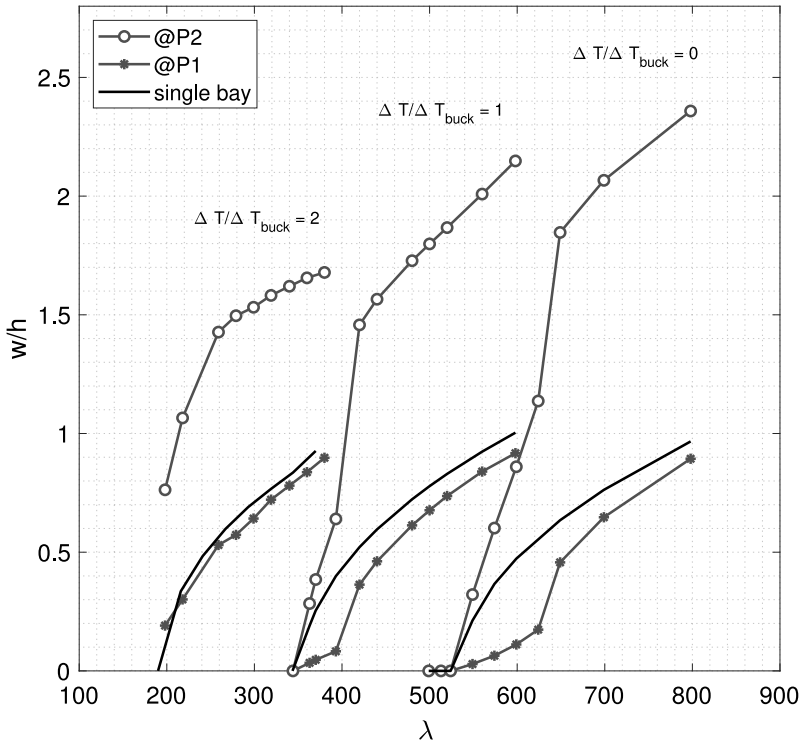

Fig. 8. Comparison of limit cycle amplitudes between a single bay and multi-bay configuration, considering $\mu / M=0.1$ and simple supported panels.

pressure, denoted as

$\lambda=\frac{2 q_{d y n} a^{3}}{D \sqrt{M^{2}-1}}$,

where $D=\left(E h^{3}\right) /\left[12\left(1-v^{2}\right)\right]$ is the plate bending stiffness parameter, $\Delta T K_{G}$ is the geometric stiffness matrix taking into account the thermal effect, $\boldsymbol{K}$ is the structural stiffness matrix, $\boldsymbol{K}_{p_{i}}$ is the penalty stiffness at the $i$ th connection line between adjacent bays, $\boldsymbol{K}_{N L_{1}}$ is the first order nonlinear structural stiffness, $\boldsymbol{K}_{N L_{2}}$ is the second order nonlinear structural stiffness, and $g \boldsymbol{C}$ is the aerodynamic damping matrix, where $g$ is the dimensionless parameter [5] associated with $\frac{\partial w}{\partial t}$ from Eq. (13),

$g=\sqrt{\frac{\lambda \mu}{\sqrt{M^{2}-1}}}\left(\frac{M^{2}-2}{M^{2}-1}\right) \simeq \sqrt{\lambda \mu / M}$,

along with $\mu=\left(\rho_{\text {air }} / \rho_{m}\right)(a / h)$ is the so-called mass ratio. Although the approximation given in Eq. (26) admits flow regimes at higher Mach numbers, for $M<3$ the flutter computation may not attain the desired precision $[24,25$

the approximation of $g$ provides adequate qualitative outcomes.

The nonlinear system represented in Eq. (24) was assessed considering sinusoidal functions as assumed modes in $x$-direction and two in the $y$-direction. The set of equations of motion is solved numerically in time using the Newmark method, similar as employed by Chen and Sun [26] and modified by Pacheco et al. [8], which takes into account damping effects. Since the aeroelastic equation of motion is homogeneous, the initial condition is considered a static deformed shape resulting from the application of a uniformly distributed pressure. From simulated time responses, bifurcation diagrams are also determined from exerting the time histories and subsequent extraction of the amplitude attained in limit cycle oscillation regime. The time integration of the equations of motion is performed adopting a small pressure distribution as initial condition.

The thermal buckling load can be obtained from the following generalized eigenvalue problem from neutral static equilibrium criterion [22],

$\left(\Delta T K_{G}+K+K_{p_{i}}\right) q(t)=\mathbf{0}$.

The non-trivial solutions of Eq. (27) reveal eigenvalues $\Delta T$, where the lowest one is the so-called critical buckling temperature variation, that is, $\Delta T_{\text {buck }}$.

\section{Model verification}

The mathematical model was initially checked with respect to the number of assumed modes that promotes convergence of the system's response. Based on the geometry giving in Fig. 1, the number of modes was varied in such way that two modes in $y$-direction were kept fix. Fig. 3 shows how the solutions for flutter dynamic pressure and the post-flutter limit cycle oscillations evolve with $\lambda$. All cases were based on the parameters given by Dowell [27]. The convergence study demonstrates that solutions start to saturate when a total of 10 modes are considered ( 5 modes in $x$-direction and 2 in $y$-direction).

Earlier results of panel flutter prediction under the effects of thermal loading were presented by Dowell [4] and Mei et al. [5]. The critical flutter condition is reached at a dynamic pressure value from which the panel oscillations stop presenting damped behavior. With the rise of the dynamic pressure value from the flutter condition one, an amplitude growth of the limit cycle oscillations is observed. This oscillatory regime leads to a Hopf bifurcation condition because of the structural geometric nonlinearity [28].

Here, the present aeroelastic model is verified under the same conditions of results established in the literature. Dowell [4] and Mei

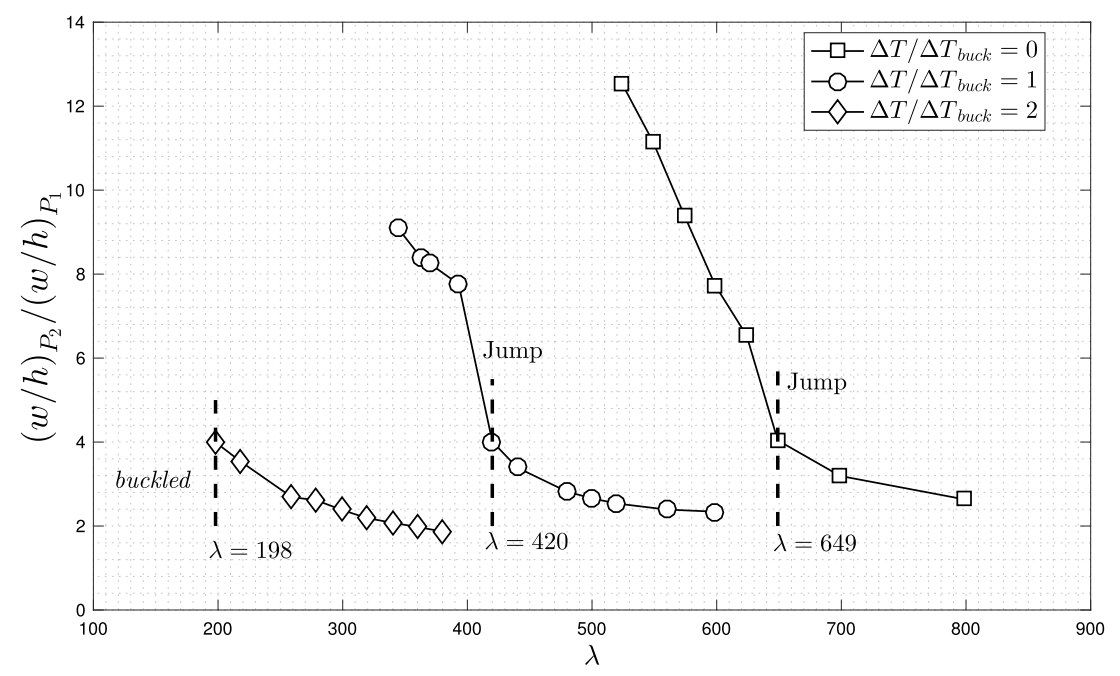

Fig. 9. Ratio of amplitudes between points $P_{1}$ and $P_{2}$ versus dynamic pressure. 

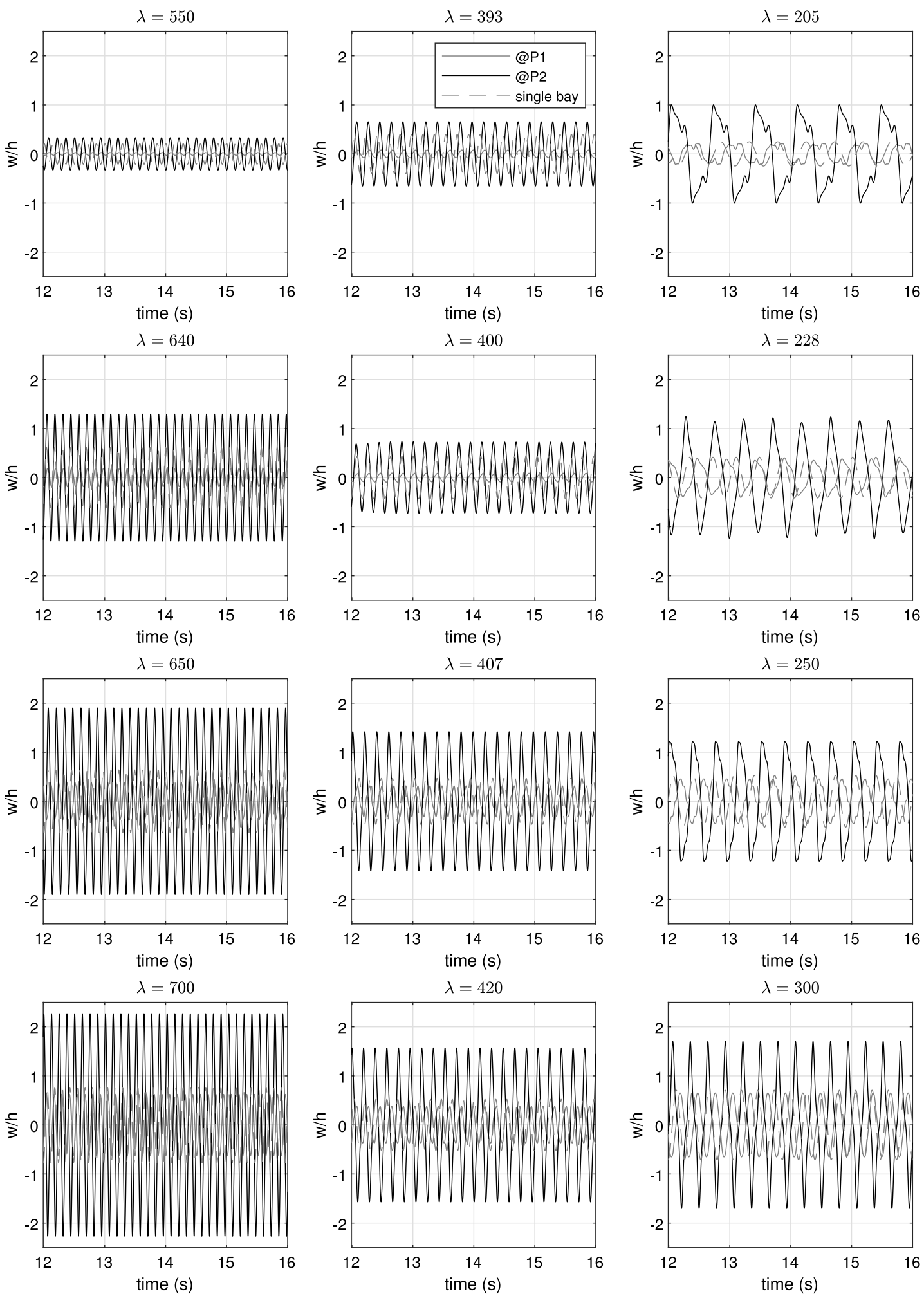

(a) $\Delta T / \Delta T_{\text {buck }}=0$

(b) $\Delta T / \Delta T_{\text {buck }}=1$

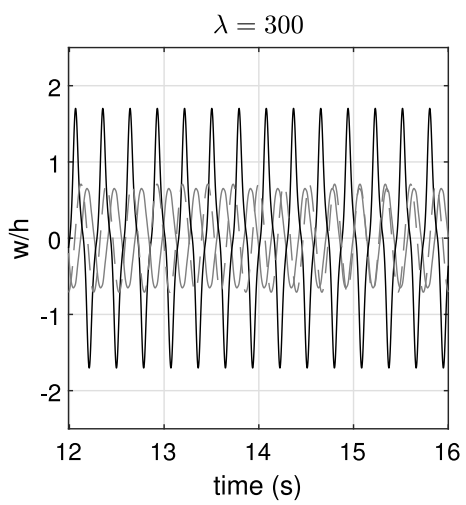

(c) $\Delta T / \Delta T_{\text {buck }}=2$

Fig. 10. Time histories for different $\Delta T / \Delta T_{\text {buck }}$ and $\lambda$ values for the single and multi-bay panels.

et al. [5] used the finite element method to model a simply supported isotropic squared plate with $a=2.43 \mathrm{~m}, h / a=0.01$, and the material's mechanical properties are $E=70 \mathrm{GPa}$ for the Young's module, and $v=0.25$ for the Poison's coefficient. Simulations were performed for Mach numbers larger than $\sqrt{2}$ to ensure the piston theory assumptions, thereby fixing the range for the dimensionless parameters. It is worth mentioning that simplified damping parameter as given in Eq. (26) yields some limitation to the results for $M<3$. Detailed discussion on this issue is provided by Vedeneev and co-workers [24,25,29]. Here, the model simplification has been considered adequate as it provides good agreement with the results by Dowell [4], as follows. Moreover, a ratio of $\mu / M=0.1$ with temperature variation $\Delta T / \Delta T_{\text {buck }}=0,1$, 

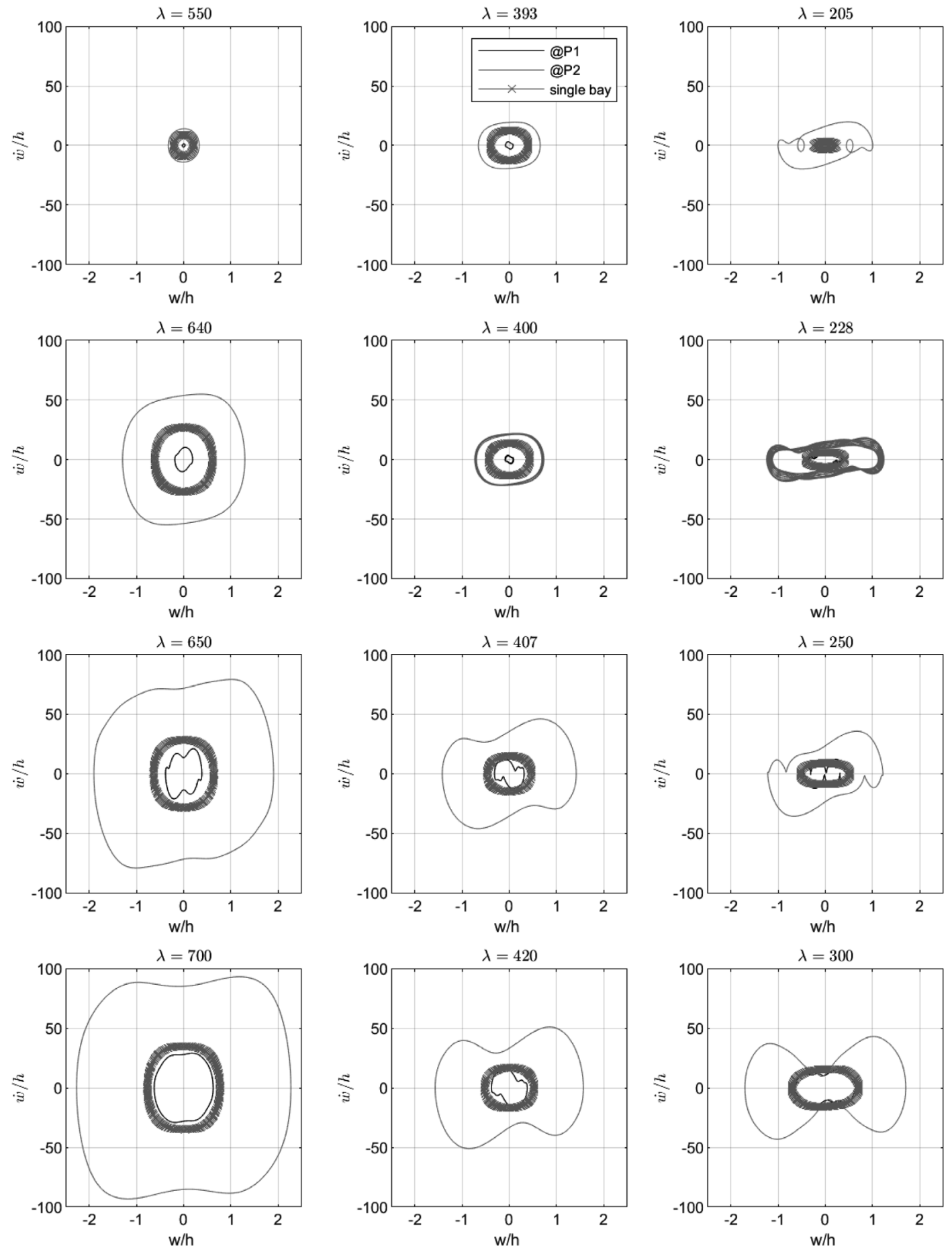

(a) $\Delta T / \Delta T_{\text {buck }}=0$

(b) $\Delta T / \Delta T_{\text {buck }}=1$

(c) $\Delta T / \Delta T_{\text {buck }}=2$

Fig. 11. Phase portrait for different $\Delta T / \Delta T_{\text {buck }}$ and $\lambda$ values for the single and multi-bay panels.

and 2 were proposed, where the buckling in-plane loads in still air is computed $N_{x x}=N_{y y}=300,770 \mathrm{Nm}$, and the thermal expansion coefficients $\boldsymbol{\alpha}=\left[\begin{array}{lll}1 & 1 & 0\end{array}\right]^{T}$. Fig. 4 compares the evolution of the limit cycle oscillations (LCO) amplitudes as a function of different operational conditions (i.e., flutter dynamic pressure and thermal conditions) assessed by Dowell [4] with those obtained with the present model. The present Rayleigh-Ritz-based model considers at least ten assumed modes. The bifurcation diagram in Fig. 4 is determined from the simulated time histories of a particular point on the structure and subsequent extraction of the limit cycle oscillation amplitude. The equations of motion is solved adopting a small pressure distribution over the panel of $100 \mathrm{~Pa}$ as an initial condition and time steps of $2.0 \times 10^{-4} \mathrm{~s}$. Results demonstrate that the Rayleigh-Ritz-based model is capable of satisfactorily predicting the flutter onset and the limit cycle oscillation amplitudes evolution with respect to the dimensionless dynamic pressure.

To emphasize the detrimental behavior of thermal loads in the linear aeroelastic solution of a single panel, one observed the first two eigenvalues $\left(\omega^{2}\right)$ evolution concerning $\lambda$ revealing the flutter onset when the respective modes coalesce. Fig. 5 depicts the respective 


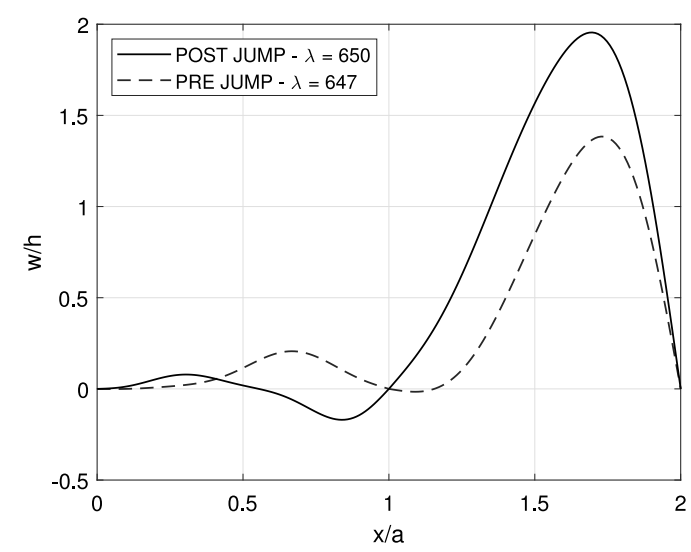

(a) $\Delta T / \Delta T_{\text {buck }}=0$

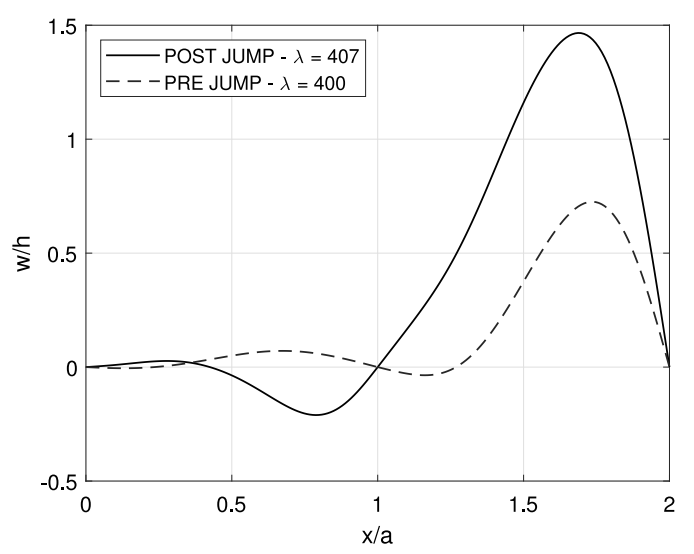

(b) $\Delta T / \Delta T_{\text {buck }}=1$

Fig. 12. Pre- and post-jump motion shapes with and without the thermal loading.

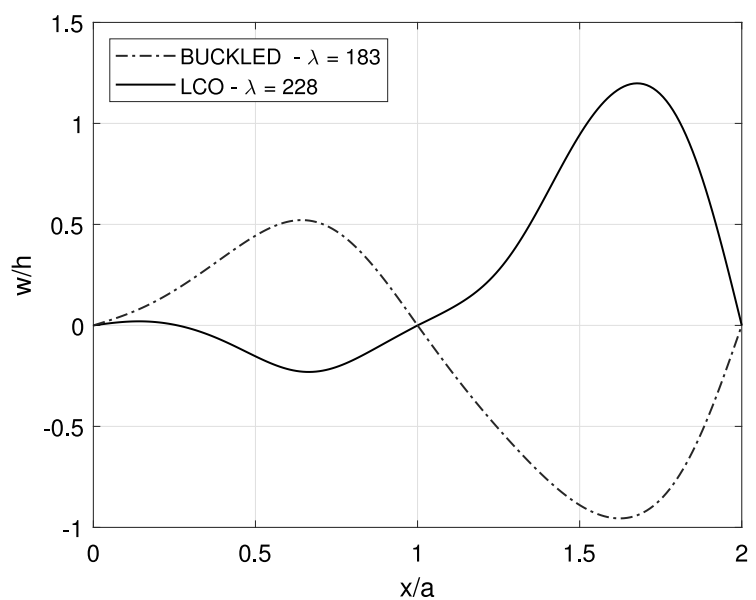

Fig. 13. Motion shapes for $\Delta T / \Delta T_{\text {buck }}=2$ revealing buckled panel prior to multi-bay panel oscillations.

aeroelastic evolution for thermal loading for $\Delta T / \Delta T_{\text {buck }}=0,1$, and 2. It worth noticing that for $\Delta T / \Delta T_{\text {buck }}=2$ the first mode is non-oscillatory for lower $\lambda$ values (that is, $\lambda<180$ ), which reveals the panel buckling. Moreover, with the increase of $\lambda$, a small stable region appears between the buckled condition and the unstable aeroelastic solution.

The differences between the single and multi-bay Hopf bifurcation behavior when the ratio $\Delta T / \Delta T_{\text {buck }}=2$ were also investigated through the time responses features. Fig. 15 depicts the time histories and the respective phase portrait of both panel configurations for $\Delta T / \Delta T_{\text {buck }}=$ 2. The comparison between both results ensures the existence of a difference at $\lambda=190$, when for the single panel the unbuckled and dynamically stable solutions are observed, in contradiction with the multi-bay panel that has a buckled configuration. Moreover, the time histories show the limit cycle oscillation amplitudes of the point $P_{2}$ are higher than at $P_{1}$, as well as a more complex orbits structure in the phase plane.

A final check of the present Rayleigh-Ritz-based model considers its simulation capabilities. Time integration of the nonlinear aeroelastic equations of motion for a square panel with $\mu / M=0.1$ and $\Delta T / \Delta T_{\text {buck }}=1.0$ was performed. The transverse displacement and velocity were taken at point $(x, y)=(3 a / 4, b / 2)$ ( $c f$. Fig. 1$)$ to yield a phase portrait as depicted in Fig. 6. Fig. 6 also includes the result obtained for the same case by Zhou et al. [23] but for a larger of dynamic pressure value. The present model simulation for $\lambda=800$ provides an adequate match with Zhou et al. [23], thereby ensuring appropriate time domain analyses features.

\section{Results and discussion}

The Rayleigh-Ritz-based model is used to assess the influence of thermal loads on the nonlinear aeroelastic behavior of multi-bay panel flutter. As a reference case, the single squared panel problem parameters are taken into account. The multi-bay case admits two simply supported adjacent square panels, each one with identical parameters as that of the verification tests of the previous Section. Particular points, one in each panel, is used to retrieve the displacement information, as illustrated in Fig. 7.

The results presented in this Section are based on the aeroelastic responses at points $P_{1}$ and $P_{2}$ due to initial conditions and time marching steps equal to that in the previous Section. Temperature variations through the ratio $\Delta T / \Delta T_{\text {buck }}=0,1$, and 2 are considered for the simulations.

The flutter onset and the post-flutter limit cycle oscillation amplitude growth at points $P_{1}$ and $P_{2}$ are depicted in Fig. 8. These oscillatory motions are characteristics of the Hopf bifurcation behavior. Three different temperature ratios were considered, and the respective square single panel case is also presented. Here, the results reveal the reduction of the flutter dynamic pressure as the temperature rises, which is related to the reduction of the panel stiffness due to the thermal effect. Indeed, the flutter onset for the multi-bay cases coincides with the single panel problem as in Fig. 4. Post-flutter oscillations clearly show the bay further downstream (point $P_{2}$ ) presenting the largest transverse displacements. The bay upstream (point $P_{1}$ ) for the different thermal loading tend to follow the single-bay amplitude values. These features can be confirmed from the time histories and phase portrait of the points $P_{1}$ and $P_{2}$ as depicted in Figs. 10 and 11, respectively for the three $\Delta T / \Delta T_{\text {buck }}$ values and some post-flutter dynamic pressures. Besides, the response of a multi-bay configuration, the time histories of a single-bay are also shown. It can be noticed that the amplitude for a single-bay is always within the interval of amplitudes defined from the amplitudes of multi-bay configuration. Moreover, as the dynamic pressure increases the limit cycle oscillation frequency also increases.

For the case where $\Delta T / \Delta T_{\text {buck }}=0$ (no thermal loading), one can observe that the limit cycle amplitudes at $P_{1}$ and $P_{2}$ have two distinct paths. After the flutter dynamic pressure $(\lambda \approx 524)$, displacement at $P_{1}$ increases in a smaller rate when compared to the displacement at $P_{2}$. Suddenly, at $\lambda>624$ the amplitudes of $P_{1}$ and $P_{2}$ increase. This jump in amplitudes has been detected by Pacheco et al. [7] that show the reason for this effect is a sudden change in motion phase allowed by the freedom in the rotation of the simply supported boundary condition between adjacent bays. The observation of Fig. 8 for the case when $\Delta T / \Delta T_{\text {buck }}=1$ indicates the same post-flutter oscillatory pattern of the no thermal loading case. Here, the flutter manifests at 


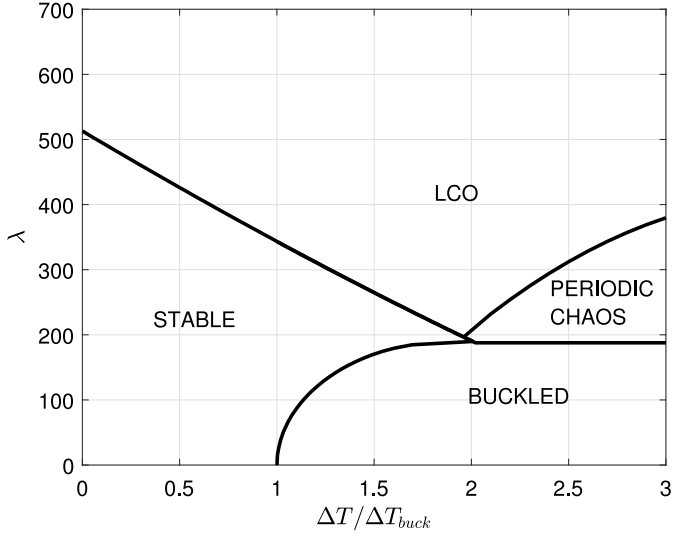

(a) Single panel

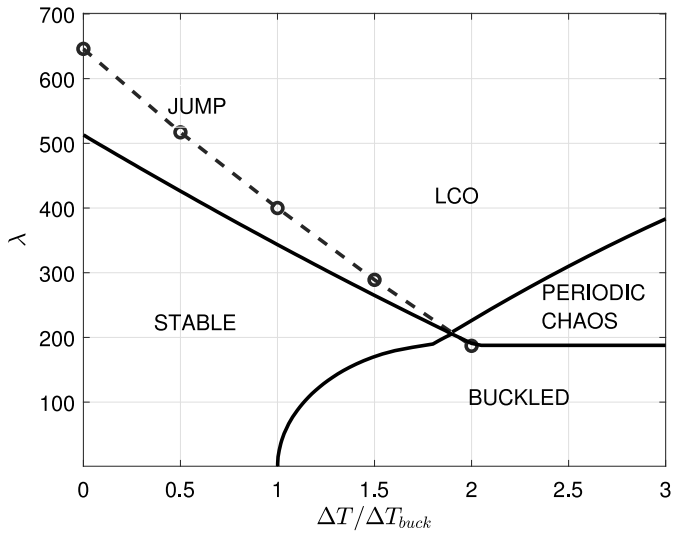

(b) Multi-bay panel

Fig. 14. Stability boundaries for the single and multi-bay panels.
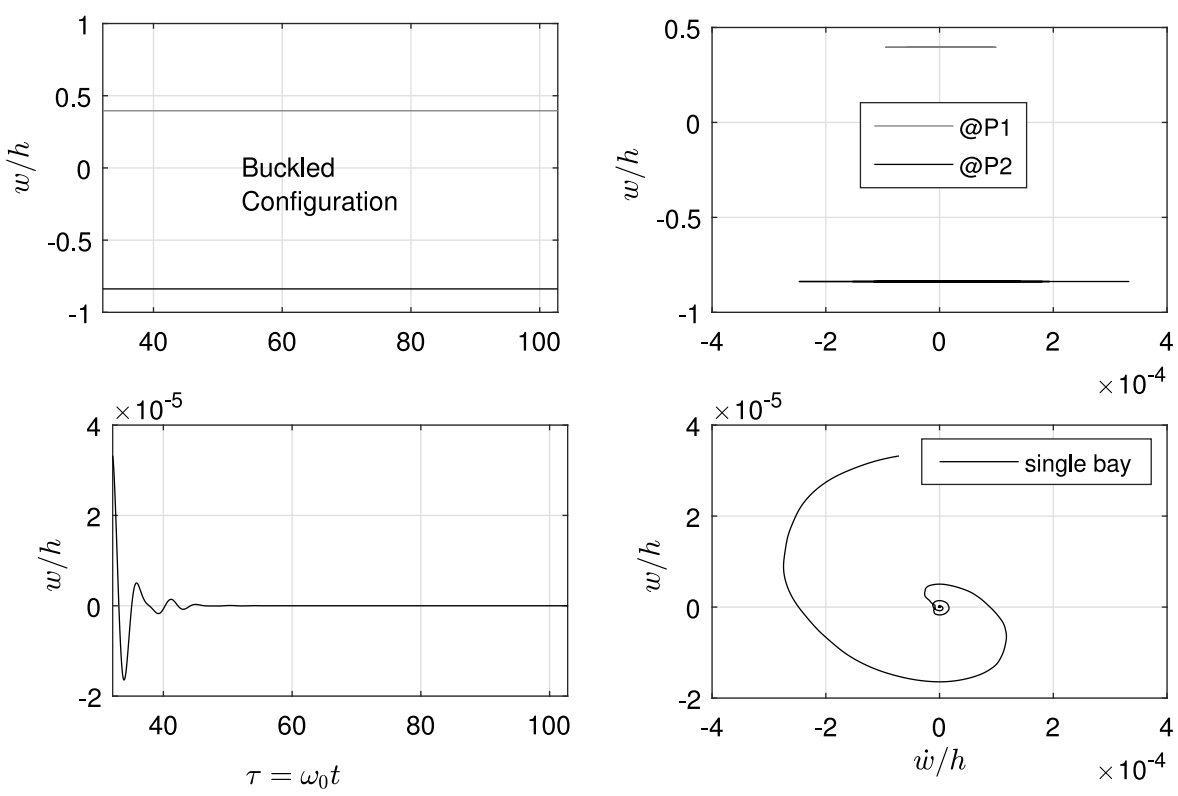

Fig. 15. Time histories and phase portrait for $\Delta T / \Delta T_{\text {buck }}=2$ and $\lambda=190$ revealing buckled panel to multi-bay panel and a stable panel for single panel configuration.

$\lambda \approx 344$ and the amplitudes of the point $P_{2}$ are slightly smaller than in the case for $\Delta T / \Delta T_{\text {buck }}=0$. A closer inspection of Fig. 8 reveals that the oscillation amplitude $w / h$ jumps from almost 0.8 to 1.5 for $\Delta T / \Delta T_{\text {buck }}=1$. Survey amplitude jump events for nonlinear multibay panel cases are important for guaranteeing the correct structural design regarding operations in supersonic flow regime. Because the thermal effect leads to stiffness reduction, these limit cycle oscillations amplitudes are smaller. The jump phenomenon is also present at $\lambda \approx$ 420 , being the upstream bay with similar amplitudes of the case with no thermal loading.

The post-flutter behavior for the cases in Fig. 8 also show different pattern of evolution between the amplitudes of points $P_{1}$ and $P_{2}$. Fig. 9 shows the ratios between the amplitudes $w / h$ at points $P_{1}$ and $P_{2}\left((w / h)_{P_{2}} /(w / h)_{P_{1}}\right)$ with respect to the dynamic pressure evolution. Except for $\Delta T / \Delta T_{\text {buck }}=2$, the pre- and post-jump conditions present different changes in the amplitudes ratio, which can be associated with different flutter mechanism.

Figs. 10 and 11 can be used to observe the $w / h$ motions at different dynamic pressures and thermal loading. It is clear the influence of temperature in the panel dynamics for the single and multi-bay cases.
Moreover, the time histories and phase portraits corroborate to show that the single bay panel post-flutter responses may be misleading, rather than considering multiple adjacent bays. Fig. 12 presents the pre- and post-jump multi-bay panel motion shapes of the panel center line coinciding with the flow direction. For the cases of no thermal loading (cf. Fig. 12(a)) and $\Delta T / \Delta T_{\text {buck }}=1$ (cf. Fig. 12(b)), it is observed that the jump phenomenon is triggered by a change in motion phase between the upstream and downstream bays, respectively, through the rotational degree of freedom at the boundary between those bays.

Figs. 8-11 at $\Delta T / \Delta T_{\text {buck }}=2$ reveals an interesting difference between the single panel solution and the multi-bay panel solution regarding the Hopf bifurcation. It means that, although a single panel solution presents a small $\lambda$ gap of stability between a buckled and a dynamically unstable configuration, the same characteristic vanishes in the multi-bay solution. Therefore, only buckled or limit cycle solutions are present. For the case where $\Delta T / \Delta T_{\text {buck }}=2$, the multi-bay flutter onset $(\lambda \approx 198)$ occurs from the buckled panel solution. Moreover, it is observed that the amplitude ratio $(w / h)_{P_{2}} /(w / h)_{P_{1}}$ versus $\lambda$, giving in Fig. 9, for $\Delta T / \Delta T_{\text {buck }}=2$ follows the same pattern as that of the postflutter in cases for $\Delta T / \Delta T_{\text {buck }}=0$ and 1. Fig. 13 illustrates the buckled 

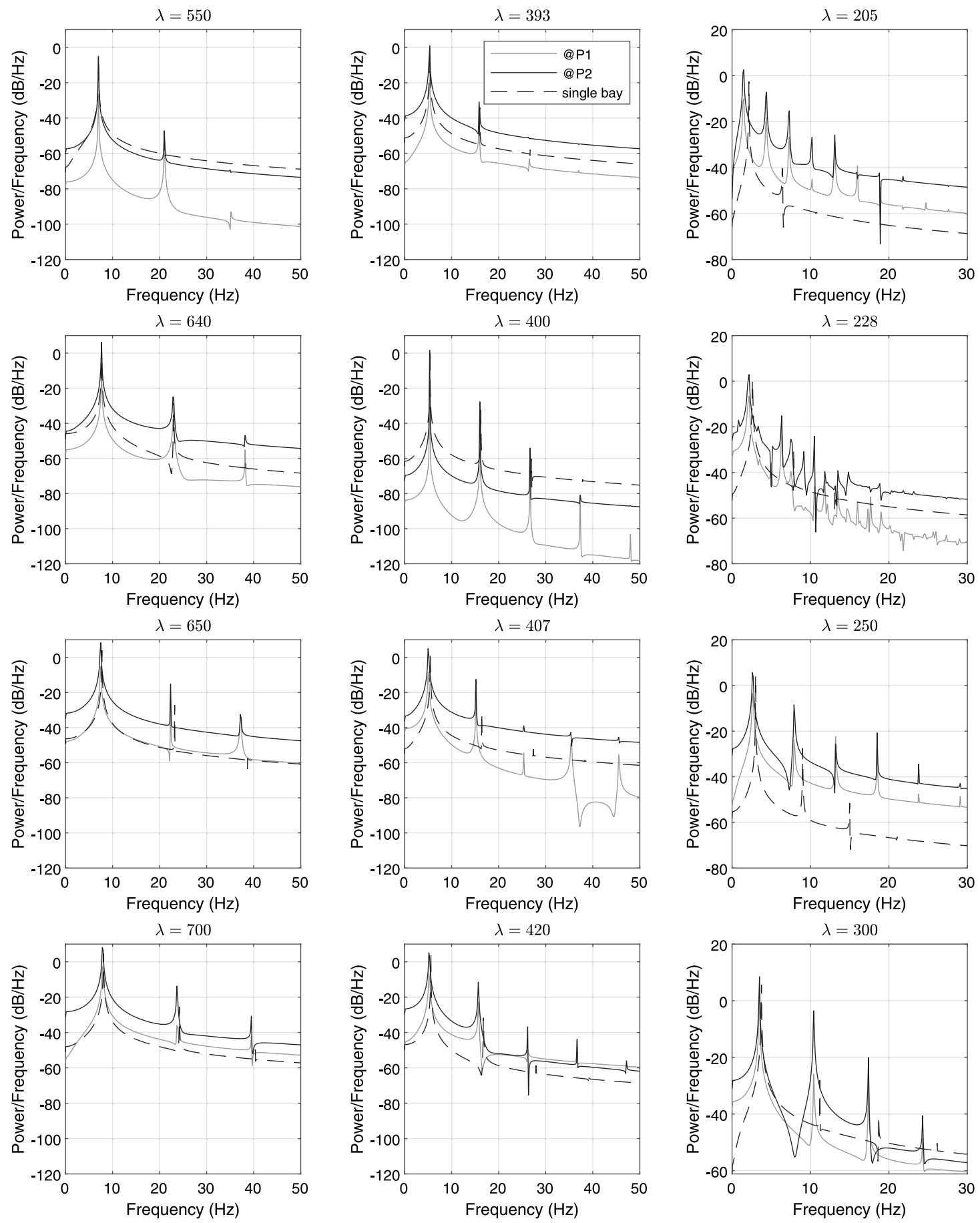

(a) $\Delta T / \Delta T_{\text {buck }}=0$

(b) $\Delta T / \Delta T_{\text {buck }}=1$

(c) $\Delta T / \Delta T_{\text {buck }}=2$

Fig. 16. Power spectra of the aeroelastic signal at different $\Delta T / \Delta T_{\text {buck }}$ and $\lambda$ values for the single and multi-bay panels.

shape of the panel together with the limit cycle oscillation shape at the panel center-line (in the flow direction). There is not an intermediate motion solution before flutter, which occurs with the bays oscillating out of phase as already observed for the pre-jump conditions for the cases in Fig. 12. The limit cycles amplitudes present much larger initial values in post-flutter range when compared to a smoother transition for lower thermal loading.

The dynamic pressure and thermal loading parameter $\Delta T / \Delta T_{\text {buck }}$ range unveils the regions for general behavior of panel in the supersonic regime. Fig. 14 provides an overview of the main dynamics for the case of single and multi-bay panels, respectively. For both cases, the stability boundaries have very similar regions regarding dynamically stable (damped solutions), buckled panel (static instability), limit cycle oscillations, and periodic and chaotic vibrations. For the single panel case (cf. Fig. 14(a)) it can be observed the typical range where thermal loading induces buckling at lower dynamic pressure excitation. At a certain level of $\lambda$, flutter manifests leading to a region of limit cycle oscillations. Temperature increments clearly show that flutter onset is also occurring for lower dynamic pressures. Fig. 14(b) reveals that for the multi-bay panel case, the buckled behavior region is similar 
to the single panel case. The results show a little anticipation of the transition from buckled to limit cycle oscillations near $\Delta T / \Delta T_{\text {buck }}=2$. A closer look to the motion shapes for multi-bay panel cases (cf. Fig. 13) allow inferring that the buckled shape works to trigger the out of phase post-jump limit cycle oscillations behavior, characteristic of the lower temperature cases.

Fig. 16 depicts the comparison of the dynamic responses spectra ( $c f$. Fig. 10) regarding dynamic pressures for single and multi-bay panels in post-flutter oscillations. Clearly, the signatures of the nonlinearity are evidenced for the cases presented through the existence of a fundamental frequency and its odd harmonics. The multi-bay configuration has the fundamental frequencies of each bay slight deviated (smaller) than that of the single panel. Moreover, the multi-bay panel presents higher energy for higher dynamic pressures regarding the single panel. An interesting aspect concerns the multi-bay panel for $\Delta T / \Delta T_{\text {buck }}=2$ and small dynamic pressures. A slight augmentation of the dynamic pressure, from $\lambda=205$ to $\lambda=228$, leads to abrupt modification of the spectrum. Regarding Fig. 16(c), one observes an increment of the signal frequency content, which is not necessarily related to the fundamental frequency. The corresponding phase portrait diagram (cf. Fig. 11) shows the trajectories for the panel positions $P_{1}$ and $P_{2}$ performing non-harmonic motion. This characteristic highlights the ability to attain potentially chaotic responses. Indeed, the Hopf bifurcation might lead to double-period responses (cf. Figs. 15(b) and 16(c)) that evolve to chaos [28].

\section{Concluding remarks}

The numerical aeroelastic analysis of multi-bay isotropic panels admitting thermal effects in the supersonic regime was presented in this paper. The multi-bay panel aeroelastic model was based on the principles of classical plate theory, geometric structural nonlinearity adopting the von Kármán strain-displacement relations, the first order piston theory unsteady aerodynamics, and a semi-analytical Ritz type model combined with a modified Newmark method for efficient time integration computation. Particular attention was devoted to the aeroelastic response with thermal loading on the post-flutter behavior between single and multi-bay panels, an issue that has not been covered in the literature to the best of the authors' knowledge. The aim is to access the temperature influence of multi-bay panels and detect differences concerning single panel cases, thereby inferring about the importance of using multi-bay panels in supersonic flutter analyses.

The numerical evaluations, as expected, highlighted the temperature detrimental aspect in the nonlinear aeroelastic behavior. Notwithstanding, the comparison between single and multi-bay panels did show significant differences regarding the nonlinear response of multi-bay panels. As stated in the literature, the existence of jumps in the limit cycle amplitudes when increasing the dynamic pressure was also captured for a range of low thermal loading. With higher temperatures, it was observed a straight transition from buckled configuration to flutter oscillations with the same post-jump out of phase motion between the adjacent bays. Moreover, the spectra results exhibit significant qualitative differences in the harmonics weight at odd multiples of the aeroelastic frequency.

Accordingly, the defined approach to evaluate the nonlinear behavior of fluttering panels with thermal effects seems to be more adequate than the standard procedure that did not take into account the connection between adjacent panels. Despite the single bay analysis generally provides reliable prediction of the flutter onset, it fails to estimate the post-flutter LCO amplitudes of interconnected bays. It corroborates with new findings in the literature that emphasizes the differences in the aeroelastic results of single and assembled panels. Further investigation on multi-bay panels analysis with thermal effects may concentrate on the influence of initial conditions on the post-flutter behavior of multi-bay panels, and a closer look at the buckled to limit cycle jump for higher thermal loading.

\section{CRediT authorship contribution statement}

Thiago A.M. Guimarães: Conceptualization, Methodology, Software, Investigation. Leonardo Sanches: Formal analysis, Methodology, Validation. Flávio D. Marques: Conceptualization, Formal analysis, Investigation.

\section{Declaration of competing interest}

The authors declare that they have no known competing financial interests or personal relationships that could have appeared to influence the work reported in this paper.

\section{Acknowledgments}

The authors acknowledge the financial support of the Brazilian Agencies: the National Council for Scientific and Technological Development (CNPq), Brazil (grant \#306824/2019-1), the Minas Gerais State Research Agency (FAPEMIG), Brazil, and São Paulo State Research Agency (FAPESP), Brazil (grants \#2017/26284-6 and \#2017/02926-9).

\section{Appendix. Matrices of the equations of motion}

$$
\begin{aligned}
& \boldsymbol{M}=h \rho_{0} \int_{0}^{a} \int_{0}^{b} \boldsymbol{S}_{w} \boldsymbol{S}_{w}^{T} d x d y, \\
& \boldsymbol{K}=\int_{0}^{a} \int_{0}^{b}\left[\begin{array}{lll}
-\frac{\partial^{2} \boldsymbol{S}_{w}}{\partial x^{2}} & -\frac{\partial^{2} \boldsymbol{S}_{w}}{\partial y^{2}} & -2 \frac{\partial^{2} \boldsymbol{S}_{w}}{\partial x \partial y}
\end{array}\right] \\
& \times \boldsymbol{D}\left[\begin{array}{lll}
-\frac{-\partial^{2} \boldsymbol{S}_{w}}{\partial x^{2}} & -\frac{\partial^{2} \boldsymbol{S}_{w}}{\partial y^{2}} & -2 \frac{\partial^{2} \boldsymbol{S}_{w}}{\partial x \partial y}
\end{array}\right]^{T} d x d y, \\
& \boldsymbol{K}_{a}=\int_{0}^{a} \int_{0}^{b} \frac{\partial \boldsymbol{S}_{w}}{\partial x} \boldsymbol{S}_{w} d x d y \\
& \boldsymbol{C}=\int_{0}^{a} \int_{0}^{b} \boldsymbol{S}_{w} \boldsymbol{S}_{w}^{T} d x d y, \\
& \boldsymbol{K}_{G}=\int_{0}^{a} \int_{0}^{b}\left(\alpha_{x} \boldsymbol{A}\left[\frac{\partial \boldsymbol{S}_{w}}{\partial x}\right]\left[\frac{\partial \boldsymbol{S}_{w}}{\partial x}\right]^{T}\right. \\
& \left.+\alpha_{y} A\left[\frac{\partial \boldsymbol{S}_{w}}{\partial y}\right]\left[\frac{\partial \boldsymbol{S}_{w}}{\partial y}\right]^{T}+2 \alpha_{x y} \boldsymbol{A}\left[\frac{\partial \boldsymbol{S}_{w}}{\partial x}\right]\left[\frac{\partial \boldsymbol{S}_{w}}{\partial y}\right]^{T}\right) d x d y, \\
& \boldsymbol{K}_{p_{i}}=\int_{0}^{b}\left(\left[\left.\frac{\partial \boldsymbol{S}_{w}}{\partial x}\right|_{\text {left }} ^{x=a} \quad \mathbf{0}\right]\left[\left.\frac{\partial \boldsymbol{S}_{w}}{\partial x}\right|_{\text {left }} ^{x=a} \quad \mathbf{0}\right]^{T}\right. \\
& \text { - }\left[\begin{array}{ll}
\mathbf{0} & \left.\frac{\partial \boldsymbol{S}_{w}}{\partial x}\right|_{\text {right }} ^{x=0}
\end{array}\right]\left[\left.\frac{\partial \boldsymbol{S}_{w}}{\partial x}\right|_{\text {left }} ^{x=a} \quad \mathbf{0}\right]^{T}- \\
& -\left[\left.\frac{\partial \boldsymbol{S}_{w}}{\partial x}\right|_{\text {left }} ^{x=a} \quad \mathbf{0}\right]\left[\begin{array}{ll}
\mathbf{0} & \left.\frac{\partial \boldsymbol{S}_{w}}{\partial x}\right|_{\text {right }} ^{x=0}
\end{array}\right]^{T} \\
& \left.+\left[\begin{array}{ll}
\mathbf{0} & \left.\frac{\partial \boldsymbol{S}_{w}}{\partial x}\right|_{\text {right }} ^{x=0}
\end{array}\right]\left[\begin{array}{ll}
\mathbf{0} & \left.\frac{\partial \boldsymbol{S}_{w}}{\partial x}\right|_{\text {right }} ^{x=0}
\end{array}\right]^{T}\right) k r_{i} d y,
\end{aligned}
$$

where the subscripts left and right denote the left and right hand side panel from the assembly line as proposed in Fig. 2.

$\boldsymbol{K}_{N L_{1}}=\boldsymbol{K}_{2}(:,:, k) \boldsymbol{q} \boldsymbol{w}^{T} \boldsymbol{K}_{m}^{-1} \boldsymbol{K}_{1}(:,:, k) \boldsymbol{q} \boldsymbol{w}^{T}$,

$\boldsymbol{K}_{N L_{2}}=\boldsymbol{q} \boldsymbol{w} \boldsymbol{K}_{3}(:,:, k, l) \boldsymbol{q} \boldsymbol{w}^{T}$,

where,

$$
\begin{aligned}
& \boldsymbol{K}_{m}=\int_{0}^{a} \int_{0}^{b}\left[\begin{array}{lll}
-\frac{\partial \boldsymbol{S}_{u}}{\partial x} & -\frac{\partial \boldsymbol{S}_{v}}{\partial y} & \left(\frac{\partial \boldsymbol{S}_{u}}{\partial y}+\frac{\partial \boldsymbol{S}_{v}}{\partial x}\right)
\end{array}\right]
\end{aligned}
$$

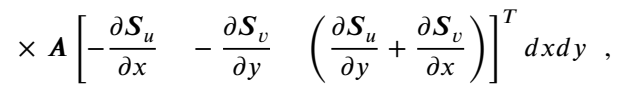

$$
\begin{aligned}
& \boldsymbol{K}_{1}(i, j, k)=\sum_{i=1}^{n u+n v} \sum_{j=n u+n v+1}^{n u+n v+n w} \sum_{k=n u+n v+1}^{n u+n v+n w} \int_{0}^{a} \int_{0}^{b}\left[\frac{A_{11}}{2}\left(\frac{\partial S u(i)}{\partial x} \frac{\partial S w(k)}{\partial x} \frac{\partial S w(j)}{\partial x}\right)+\right.
\end{aligned}
$$




$$
\begin{array}{lll}
+\frac{A_{21}}{2}\left(\frac{\partial S v(i)}{\partial y} \frac{\partial S w(k)}{\partial x} \frac{\partial S w(j)}{\partial x}\right) & +\frac{A_{13}}{2}\left(\frac{\partial S w(i)}{\partial y} \frac{\partial S w(k)}{\partial x} \frac{\partial S w(l)}{\partial x} \frac{\partial S w(j)}{\partial x}\right)+ \\
+\frac{A_{31}}{2}\left(\frac{\partial S u(i)}{\partial y} \frac{\partial S w(k)}{\partial x} \frac{\partial S w(j)}{\partial x}+\frac{\partial S v(i)}{\partial x} \frac{\partial S w(k)}{\partial x} \frac{\partial S w(j)}{\partial x}\right)+ & +\frac{A_{23}}{2}\left(\frac{\partial S w(i)}{\partial y} \frac{\partial S w(k)}{\partial y} \frac{\partial S w(l)}{\partial x} \frac{\partial S w(j)}{\partial y}\right)+ \\
+\frac{A_{12}}{2}\left(\frac{\partial S u(i)}{\partial x} \frac{\partial S w(k)}{\partial y} \frac{\partial S w(j)}{\partial y}\right) & +A_{33}\left(\frac{\partial S w(i)}{\partial x} \frac{\partial S w(k)}{\partial y} \frac{\partial S w(l)}{\partial y} \frac{\partial S w(j)}{\partial x}\right. \\
+\frac{A_{32}}{2}\left(\frac{\partial S u(i)}{\partial y} \frac{\partial S w(k)}{\partial y} \frac{\partial S w(j)}{\partial y}+\frac{\partial S v(i)}{\partial x} \frac{\partial S w(k)}{\partial y} \frac{\partial S w(j)}{\partial y}\right)+ & \left.\left.+\frac{\partial S w(i)}{\partial y} \frac{\partial S w(k)}{\partial x} \frac{\partial S w(l)}{\partial x} \frac{\partial S w(j)}{\partial y}\right)\right] d x d y,
\end{array}
$$$$
+\frac{A_{22}}{2}\left(\frac{\partial S v(i)}{\partial y} \frac{\partial S w(k)}{\partial y} \frac{\partial S w(j)}{\partial y}\right)+A_{13}\left(\frac{\partial S u(i)}{\partial x} \frac{\partial S w(k)}{\partial x} \frac{\partial S w(j)}{\partial y}\right)
$$$$
+A_{23}\left(\frac{\partial S v(i)}{\partial y} \frac{\partial S w(k)}{\partial x} \frac{\partial S w(j)}{\partial y}\right)+
$$$$
\left.+A_{33}\left(\frac{\partial S u(i)}{\partial y} \frac{\partial S w(k)}{\partial x} \frac{\partial S w(j)}{\partial y}+\frac{\partial S v(i)}{\partial x} \frac{\partial S w(k)}{\partial x} \frac{\partial S w(j)}{\partial y}\right)\right] d x d y,
$$$$
\boldsymbol{K}_{2}(i, j, k)=\sum_{i=n u+n v+1}^{n u+n v+n w} \sum_{j=1}^{n u+n v} \sum_{k=n u+n v+1}^{n u+n v+n w} \int_{0}^{a} \int_{0}^{b}\left[A_{11}\left(\frac{\partial S w(i)}{\partial x} \frac{\partial S w(k)}{\partial x} \frac{\partial S u(j)}{\partial x}\right)+\right.
$$$$
+A_{21}\left(\frac{\partial S w(i)}{\partial y} \frac{\partial S w(k)}{\partial y} \frac{\partial S u(j)}{\partial x}\right)
$$$$
+A_{31}\left(\frac{\partial S w(i)}{\partial x} \frac{\partial S w(k)}{\partial y} \frac{\partial S u(j)}{\partial x}+\frac{\partial S w(i)}{\partial y} \frac{\partial S w(k)}{\partial x} \frac{\partial S u(j)}{\partial x}\right)+
$$$$
+A_{12}\left(\frac{\partial S w(i)}{\partial x} \frac{\partial S w(k)}{\partial x} \frac{\partial S v(j)}{\partial y}\right)
$$$$
+A_{32}\left(\frac{\partial S w(i)}{\partial x} \frac{\partial S w(k)}{\partial y} \frac{\partial S v(j)}{\partial y}+\frac{\partial S w(i)}{\partial y} \frac{\partial S w(k)}{\partial x} \frac{\partial S v(j)}{\partial y}\right)+
$$$$
+A_{22}\left(\frac{\partial S w(i)}{\partial y} \frac{\partial S w(k)}{\partial y} \frac{\partial S v(j)}{\partial y}\right)
$$$$
+A_{13}\left(\frac{\partial S w(i)}{\partial x} \frac{\partial S w(k)}{\partial x} \frac{\partial S u(j)}{\partial y}+\frac{\partial S w(i)}{\partial x} \frac{\partial S w(k)}{\partial x} \frac{\partial S v(j)}{\partial x}\right)+
$$$$
+A_{23}\left(\frac{\partial S w(i)}{\partial y} \frac{\partial S w(k)}{\partial y} \frac{\partial S u(j)}{\partial y}+\frac{\partial S w(i)}{\partial y} \frac{\partial S w(k)}{\partial y} \frac{\partial S v(j)}{\partial x}\right)+
$$$$
+A_{33}\left(\frac{\partial S w(i)}{\partial x} \frac{\partial S w(k)}{\partial y} \frac{\partial S u(j)}{\partial y}+\frac{\partial S w(i)}{\partial x} \frac{\partial S w(k)}{\partial y} \frac{\partial S v(j)}{\partial x}+\right.
$$$$
\left.\left.+\frac{\partial S w(i)}{\partial y} \frac{\partial S w(k)}{\partial x} \frac{\partial S u(j)}{\partial y}+\frac{\partial S w(i)}{\partial y} \frac{\partial S w(k)}{\partial x} \frac{\partial S v(j)}{\partial x}\right)\right] d x d y,
$$$$
\boldsymbol{K}_{3}(i, j, k, l)=\sum_{i=n u+n v+1}^{n u+n v+n w} \sum_{j=n u+n v+1}^{n u+n v+n w} \sum_{k=n u+n v+1}^{n u+n v+n w} \sum_{l=n u+n v+1}^{n u+n v+n w} \int_{0}^{a} \int_{0}^{b}\left[\frac{A_{11}}{2}\right.
$$$$
\times\left(\frac{\partial S w(i)}{\partial x} \frac{\partial S w(k)}{\partial x} \frac{\partial S w(l)}{\partial x} \frac{\partial S w(j)}{\partial x}\right)+
$$$$
+\frac{A_{21}}{2}\left(\frac{\partial S w(i)}{\partial y} \frac{\partial S w(k)}{\partial x} \frac{\partial S w(l)}{\partial x} \frac{\partial S w(j)}{\partial y}\right)+
$$$$
+\frac{A_{31}}{2}\left(\frac{\partial S w(i)}{\partial x} \frac{\partial S w(k)}{\partial x} \frac{\partial S w(l)}{\partial x} \frac{\partial S w(j)}{\partial y}\right.
$$$$
\left.+\frac{\partial S w(i)}{\partial y} \frac{\partial S w(k)}{\partial x} \frac{\partial S w(l)}{\partial x} \frac{\partial S w(j)}{\partial x}\right)+
$$$$
+\frac{A_{12}}{2}\left(\frac{\partial S w(i)}{\partial x} \frac{\partial S w(k)}{\partial y} \frac{\partial S w(l)}{\partial y} \frac{\partial S w(j)}{\partial x}\right)
$$$$
+\frac{A_{22}}{2}\left(\frac{\partial S w(i)}{\partial y} \frac{\partial S w(k)}{\partial y} \frac{\partial S w(l)}{\partial y} \frac{\partial S w(j)}{\partial y}\right)+
$$$$
+\frac{A_{32}}{2}\left(\frac{\partial S w(i)}{\partial x} \frac{\partial S w(k)}{\partial y} \frac{\partial S w(l)}{\partial y} \frac{\partial S w(j)}{\partial y}\right.
$$$$
\left.+\frac{\partial S w(i)}{\partial y} \frac{\partial S w(k)}{\partial y} \frac{\partial S w(l)}{\partial y} \frac{\partial S w(j)}{\partial x}\right)+
$$

where $n u, n v$, and $n w$ represents the lengths of vectors $q u, q v$, and $q w$ respectively, and $A_{i j}$ are the elements of matrix $\boldsymbol{A}$ (cf. Eq. (7)).

\section{References}

[1] E.H. Dowell, Aeroelasticity of Plates and Shells, Noordhoff International Publishing, 1975.

[2] M. Amabili, F. Pellicano, Nonlinear supersonic flutter of circular cylindrical shells, AIAA J. 39 (4) (2001) 564-573, http://dx.doi.org/10.2514/2.1365.

[3] M. Amabili, Nonlinear Vibrations and Stability of Shells and Plates, first ed., Cambridge University Press, New York, USA, 2008.

[4] E.H. Dowell, Panel flutter - A review of the aeroelastic stability of plates and shells, AIAA J. 8 (3) (1970) 385-399, http://dx.doi.org/10.2514/3.5680.

[5] C. Mei, K. Abdel-Motagaly, R. Chen, Review of nonlinear panel flutter at supersonic and hypersonic speeds, Appl. Mech. Rev. 52 (1999) 321-332, http: //dx.doi.org/10.1115/1.3098919.

[6] D.R.Q. Pacheco, F.D. Marques, A.J.M. Ferreira, Nonlinear finite element aeroelastic analysis of multibay panels in supersonic flow regime, Thin-Walled Struct. 120 (2017) 470-478, http://dx.doi.org/10.1016/j.tws.2017.08.034.

[7] D.R.Q. Pacheco, A.J.M. Ferreira, F.D. Marques, On the effects of structural coupling on the supersonic flutter and limit cycle oscillations of transversely reinforced panels, J. Fluids Struct. 79 (2018) 158-170, http://dx.doi.org/10. 1016/j.jfluidstructs.2018.01.013.

[8] D.R.Q. Pacheco, F.D. Marques, A.J.M. Ferreira, Finite element analysis of fluttering plates reinforced by flexible beams: An energy-based approach, J. Sound Vib. 435 (2018) 135-148, http://dx.doi.org/10.1016/j.jsv.2018.07.042.

[9] E.H. Dowell, Flutter of multibay panels at high supersonic speeds, AIAA J. 2 (10) (1964) 1805-1814, http://dx.doi.org/10.2514/3.2669.

[10] E.H. Dowell, On the flutter of multibay panels at low supersonic speeds, AIAA J. 5 (5) (1967) 1032-1033, http://dx.doi.org/10.2514/3.4125.

[11] W.P. Rodden, Flutter of multibay panels at supersonic speeds, AIAA J. 2 (8) (1964) 1476-1478, http://dx.doi.org/10.2514/3.2614.

[12] M.H. Lock, E.F. Farkas, Flutter of two-bay flat panels of infinite span at supersonic Mach numbers, AIAA J. 3 (9) (1965) 1692-1697, http://dx.doi.org/ $10.2514 / 3.3228$.

[13] T.A.M. Guimarães, F.D. Marques, A.J.M. Ferreira, On the modeling of nonlinear supersonic flutter of multibay composite panels, Compos. Struct. 232 (2020) http://dx.doi.org/10.1016/j.compstruct.2019.111522.

[14] J.N. Reddy, Mechanics of Laminated Composite Plates and Shells: Theory and Analysis, second ed., CRC Press, 2004.

[15] R.R. Craig, A.J. Kurdila, Fundamentals of Structural Dynamics, Wiley, 2006.

[16] H. Ashley, G. Zartarian, Piston theory - A new aerodynamic tool for the aeroelastician, J. Aeronaut. Sci. 23 (12) (1956) 1109-1118, http://dx.doi.org/ $10.2514 / 8.3740$.

[17] S.C. Nixon, Comparison of Panel Flutter Results from Approximate Aerodynamic Theory with Results from Exact Inviscid Theory and Experiment, Technical Report, NASA Langley Research Center - NASA TN D-3649, 1966.

[18] M. Amabili, F. Pellicano, Multimode approach to nonlinear supersonic flutter of imperfect circular cylindrical shells, J. Appl. Mech. 69 (2) (2001) 117-129, http://dx.doi.org/10.1115/1.1435366.

[19] M. Amabili, I.D. Breslavsky, Displacement dependent pressure load for finite deflection of doubly-curved thick shells and plates, Int. J. Non-Linear Mech. 77 (2015) 265-273, http://dx.doi.org/10.1016/j.ijnonlinmec.2015.09.007.

[20] M. Amabili, Nonlinear Mechanics of Shells and Plates: Composite, Soft and Biological Materials, Cambridge University Press, New York, USA, 2018.

[21] S.G.P. Castro, T.A.M. Guimarães, D.A. Rade, M.V. Donadon, Flutter of stiffened composite panels considering the stiffener's base as a structural element, Compos. Struct. 140 (2016) 36-43, http://dx.doi.org/10.1016/j.compstruct.2015.12.056.

[22] S.G.P. Castro, M.V. Donadon, Assembly of semi-analytical models to address linear buckling and vibration of stiffened composite panels with debonding defect, Compos. Struct. 160 (2017) 232-247, http://dx.doi.org/10.1016/j.compstruct. 2016.10.026.

[23] R.C. Zhou, D.Y. Xue, C. Mei, Finite element time domain - Modal formulation for nonlinear flutter of composite panels, AIAA J. 32 (10) (1994) 2044-2052, http://dx.doi.org/10.2514/3.12250.

[24] V.V. Vedeneev, Panel flutter at low supersonic speeds, J. Fluids Struct. 29 (2012) 79-96, http://dx.doi.org/10.1016/j.jfluidstructs.2011.12.011. 
[25] S. Shitov, V.V. Vedeneev, Flutter of rectangular simply supported plates at low supersonic speeds, J. Fluids Struct. 69 (2017) 154-173, http://dx.doi.org/10. 1016/j.jfluidstructs.2016.11.014.

[26] J.K. Chen, C.T. Sun, Nonlinear transient responses of initially stressed composite plates, Comput. Struct. 21 (3) (1985) 513-520, http://dx.doi.org/10.1016/00457949(85)90130-0.

[27] E.H. Dowell, Nonlinear oscillations of a fluttering plate, AIAA J. 4 (7) (1966) 1267-1275, http://dx.doi.org/10.2514/3.3658.
[28] A.H. Nayfeh, B. Balachandran, Applied Nonlinear Dynamics: Analytical, Computational, and Experimental Methods, John Wiley \& Sons, New York, 1995.

[29] A. Shishaeva, V. Vedeneev, A. Aksenov, G. Sushko, Transonic panel flutter in accelerating or decelerating flow conditions, AIAA J. 56 (3) (2018) 997-1010, http://dx.doi.org/10.2514/1.J056217. 